\title{
Partner Perspectives-The Harsh Reality of Pursuing Innovations
}

\author{
Vietnamica \\ Stratfor Worldview \\ Stratfor WORLDVIEW
}

Nov 3, 2014

https:// worldview.stratfor.com/article/ harsh-reality-pursuing-innovations-emergingmarket-perspectives 


\section{The Harsh Reality of Pursuing Innovations: Emerging Market Perspectives}

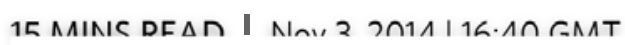




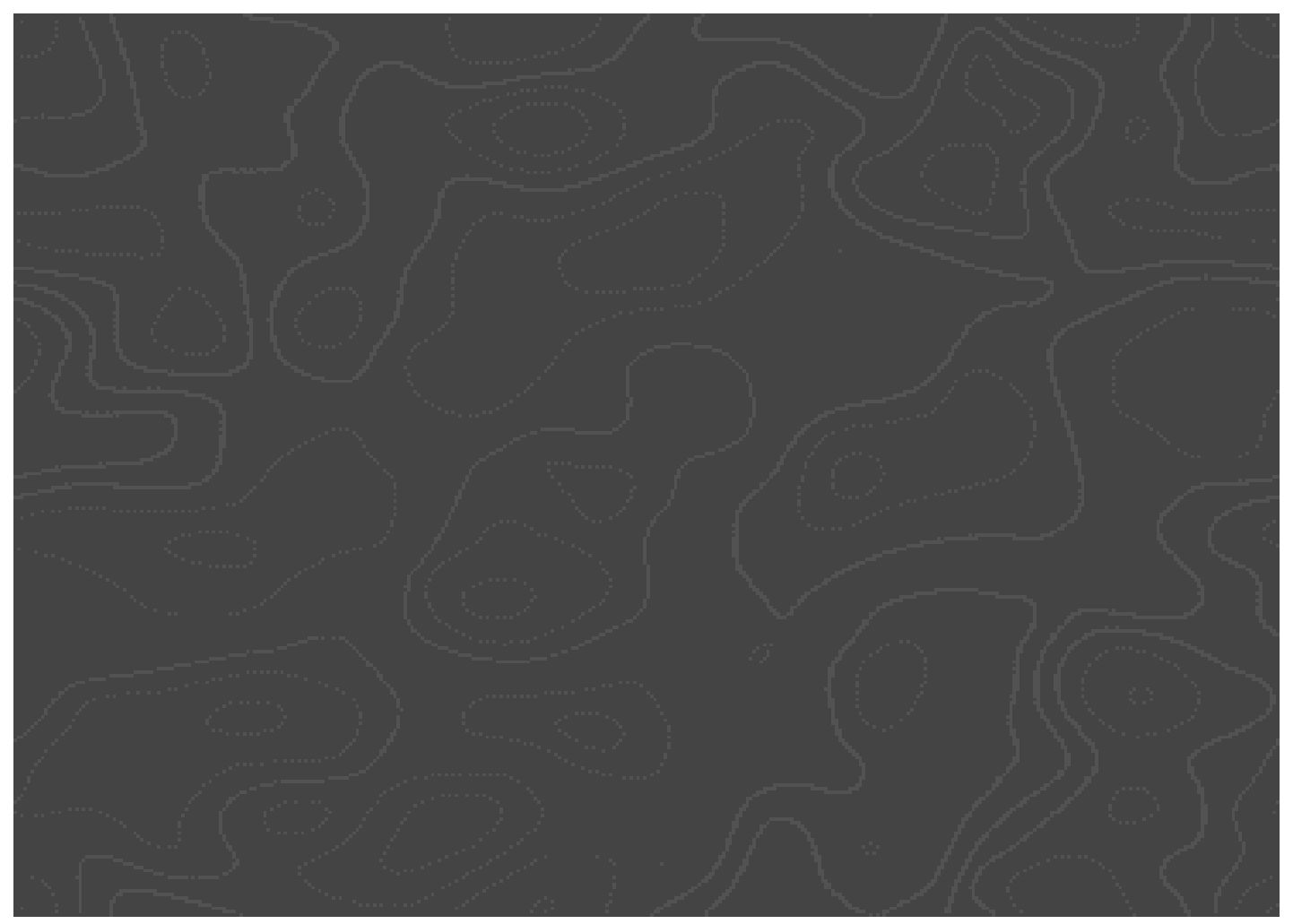

\section{November 3, 2014 for Vietnamica}

We start with a common understanding of innovation as the process of creating new "things" out of useful and novel ideas, followed by creating new values once the "new things" become goods and/or services accepted by customers in the marketplace. It is the degree of 'usefulness' and 'novelty' that will determine the possible value a customer may realize, and thus a firm may gain when providing them to the market.

\section{Innovation in entrepreneurial processes and capitalist economic systems}

Indeed, innovation capacity largely defines the destiny of entrepreneurial endeavors. Vuong, Napier, and Tran's (2013) investigation of 115 individual respondents into business successes in Vietnam reveals that innovation plays a critical role in the 'entrepreneurial stage' of a business lifecycle while traditional cultural values, to a large extent, adversely affect entrepreneurial spirit of the community (Vuong and Tran, 2009). Empirical evidence also shows that the relationship between business approach (i.e., rent-seeking vs. creativity making) and corporate orientation (i.e., tapping out resources or seeking prospective markets) is the best-fit predictor of financial failure and fraud (Vuong, Napier, Tran, and Nguyen, 2013) as well as post-M\&A performance (Vuong, Napier, and Samson, 2014).

Consequently, it is hard to imagine a genuine entrepreneurial effort without some innovative capacity. Even when the champions admire their success for serendipitous stories, we argue that they employed "serendipity-based" creativity methods to serve as strategic advantage (Napier and Vuong, 2013). Being continuous innovators or continuously creating knowledge is a necessity if companies want to survive fierce competition, and pursue business success 
(Nonaka, 1991). Innovation very often arrives unexpectedly - "Je ne cherche pas, je trouve" as famously put by Picasso - but the innovative outcomes result from a disciplined process (Vuong and Napier, 2014). Innovation as perceived by us today represents a key characteristic of any entrepreneurial process, and usually is at the heart of a typical entrepreneurial attempt.

The ability to innovate largely determines a firm's success in an increasingly fierce market competition in today's globalizing world economy. Unfortunately, this capacity does not come easily, and is oftentimes result of serious commitment, long-standing efforts and even costly expenditure. In Asia, the leading economy of Japan in 1980s and 1990s serves as an example of lasting achievements, involving a process of in-company knowledge creation as well (Nonaka, 1991).

Nowadays, we also notice that failure to innovate would likely lead to negative impacts of the universal law of diminishing returns. But, a relatively small percentage of innovations have achieved success, and unwise R\&D investments could also lead to diminishing competitiveness and financial consequences. This dilemma is a reality of capitalist economic models, and may have more profound impacts in emerging markets where the institution building process is underway and incomplete.

\section{Advantages and disadvantages for developing countries in making innovation}

\section{Advantages:}

Most developing economies struggle to escape from the stagnant "lower-middle income" stratum. Generally speaking, they have an innate desire to make new things happen, oftentimes striving for practical innovations in both products, processes and business models as practical options.

All developing countries face the problem of economic efficiency, and their problems can even be exacerbated by the presence of the "resource curse" problem. Fiercer competitive environments and a lack of genuine entrepreneurs tend to worsen the problem of resource misallocation in transition turmoil where ex-ante resource-rich firms imitate the business model and strategy and cause "destructive creation" (Vuong and Napier, 2014a).

It is now a common understanding that innovation capacity could help address these issues, and in many cases serves as the only major and credible solution to address them.

Not all types of innovation are too costly for developing countries to make and/or adopt, and both the globalizing world and fast-improving ICT infrastructure have helped reduce the cost of accessing the new knowledge and information so critical to "innovators". Now, it is not uncommon that the two notions are mixed up, and it is time to revisit Albert Einstein's remark that "information is not knowledge."

On the other hand, an entrepreneurial orientation whilst proving to be critically important to an entrepreneurship pathway is enough to merely start the quest. Adoption of a disciplined multi-filtered information process is necessary (Vuong 
and Napier, 2014). Fortunately, economics and business literature has become very rich regarding assessment, evaluation and guidance on the use of ICT systems as well as information components serving the needs of both innovators and innovating institutions.

\section{Disadvantages:}

Both external and internal environments in developing countries appear to have been less favorable to innovation efforts. Asymmetric and imperfect market settings - which are dominated by interest groups and monopolists - encourage rent-seeking efforts to capture business privileges (Vuong, 2014). When cost-benefit considerations and market outlook are simply ignored, building innovation capacity - which is often lonely and tedious (Vuong et al., 2014) - is certainly downplayed. While scrambling for privilege or inside information people may overspend on building relationships, creating bizarre business games and covering up gimmicks. It is so easy for fundraisers to set up Ponzi schemes when both naïve individuals and veteran professionals are ready to construct high expectations by hyped stories. Last but not least, eroding society's trust is more worrisome.

Dependence on export markets can be a source of risk, but independence may imply a real limit due the size of domestic market. This dilemma is never easy to solve at the macro level, and becomes very real at the firm's decision-making level. Fortunately, Schumpeter (1942[1994]) shows a natural solution, and also inexorable reality, to this, the "creative destruction" process. And to make this happen, corporate culture needs to create an entrepreneurial space, in which the motion of "creative quanta" faces as little friction as possible (Vuong and Napier, 2014).

Overestimating the value of home-grown innovations by smaller firms-SMEs outnumber other firms-in developing countries is another disadvantage. Business owners - very often leaders in SMEs - certainly play a pivotal role in a firm's innovation process. They start businesses with an innovation, i.e., a new product/service, a new process of production, or a new business model. But struggling with scaling up and focusing on dealing with daily challenges may prevent them from continuous innovation. Early success may also contribute to myopic vision and arrogance.

Weak financial positions of smaller innovating firms may subject innovators to tricky game of M\&A, representing both payoffs and foregone earnings. Vuong, Napier and Samson (2014) affirm that innovation and creative performance are critical important factors to pursue in M\&A transactions. To this end, both the acquired and the acquirer should pay more attention to capable and willing [to pursue innovation] human capital than physical resources or existing values of corporate brands.

Overemphasis on innovation coupled with financial failures could lead to worsening problems of monopoly / oligopoly as the concentration in marketplace continues, and the large firms tend to amass more wealth and power over time, in many cases at the expense of smaller and innovative firms that die young.

The harsh reality 
Most entrepreneurs do not realize that only a small percentage of innovations have been adopted into industrial commercialization and of these, only a small percentage of adopted innovations have reaped financial payoffs.

Firms should also beware of abusing innovation. Scrambling for innovation may cause an entrepreneurial curse of innovation (Maddock, 2013). Finding innovative ideas is challenging but still much easier than transforming them into commercial products and services that are accepted by consumers and clients. The commercialization process of innovation is often costly, requiring enormous effort in innovative solutions to marketing, cost optimization, effective distribution and the likes. Entrepreneurs who trust in the power of innovation may fall into the "innovation trap" - a potential failure of business. That is, instead of being innovators who first find the largest unmet demand then innovate products, services, solutions to market's problems, many are inventors who start with their innovative thinking then try to convince market to buy what they offer. Persuading the market can be a tricky game, and tends to be time-consuming and financially costly.

Unlike what we heard about the "universal value of market systems", arm's length transactions and earnest market competition are not universal values and ubiquitous rules that economies and firms observe and follow. This is particularly true in environments where personal connections and relationship-based rentseeking are rampant.

Unlike the theoretical reasoning of values that innovations would likely bring about, evidence of success and payoffs innovating firms enjoy can be mixed and sometimes very confusing. For example, many IT firms are offering internet-based gold and forex trading platforms which try to assure investors of high earnings on the high-risk financial games. Realistic investors know that these benefits are surreal. In reality, innovation-based entrepreneurial efforts could be as fruitless as any other bad economic models.

The emerging market - where labor forces are ready and efforts to innovate exist can be a trap where investors' money and good will are spent in the worst way possible, due to various reasons and mistakes, including subjective and mistaken calculation of market forces and timing.

It is not uncommon that the nice idea of "making innovations" might be also manipulated by majority shareholders in public firms to become a reason for spending spree and various financial market games including M\&A. Resource curse problems may worsen in these circumstances.

\section{When the dust settles}

\section{What we have learned}

Making a fuss about innovation makes little sense, but long-term and earnest interests in creative performance, and particularly in innovation, help capture opportunities in a fast-closing window of today's dynamic business world. 
Creative methods and appropriate corporate policies tend to define the efficiency of the innovation process itself, but innovation per se does not determine the success of an innovating firm. The market does.

Entering the innovation game would clearly mean innovating firms would have little choice but to accept the rules of game, and to survive serious tests of efficiency, local optimality and "durability." These are by no means determined by the game player, and usually decided by externalities that a firm can only predict (ex ante) and learn (ex post).

Thus, over excitement about innovation cannot replace appropriate methodology of organizing the business process, disciplines for pursuing desired outcomes, and tools/techniques for measuring efficiency as well as effectiveness of such important, and oftentimes tricky, pursuits.

\section{“i2Metrix program”: an on-going experiment}

This "i2Metrix program" is an initiative by a number of researchers and business consultants to design a framework for assessing the innovative capacity of corporate organizations.[1] The framework measures different aspects of a business operation relating to actual and potential capabilities of firms to pursue innovation. More details about the survey design and descriptions of metrics are provided in Vuong et al (2014). Numerical values are assigned to each participatory firm's ten dimensions as shown in the two charts below.

The survey started out in early 2014, and by the end of February, 19 firms of larger size - that are members of the group of established companies in Vietnam, called LBC - became pioneers participating the program.

By end of June, the total number of firms participating in this i2Metrix program increased to 25. After the most recent round of survey, which ended mid-October, data was collected from 40 firms, most of which are Vietnamese manufacturing, food processing, and pharmaceutical companies.

These 40 firms collectively generated total revenue of approximately $\$ 2$ billion in 2013 , with an estimated growth of $15 \%$ on average in 2014 . They currently employ about 35,000 people, and genuinely serve as a typical "growth engine" for the emerging market economy of Vietnam. These firms come from 11 different provinces of Vietnam, consisting of different types, sizes and fields of business.

In Figure 1, average numerical values for factors measured are presented for three rounds of survey, following which the sample has expanded. Values have decreased when smaller and less successful firms joined the survey. Still, on average these firms perform quite well, as the majority of them have been "veterans" in the marketplace and survived tough competition in the past. Their leaders appear to appreciate the value of innovation and they do innovate. 


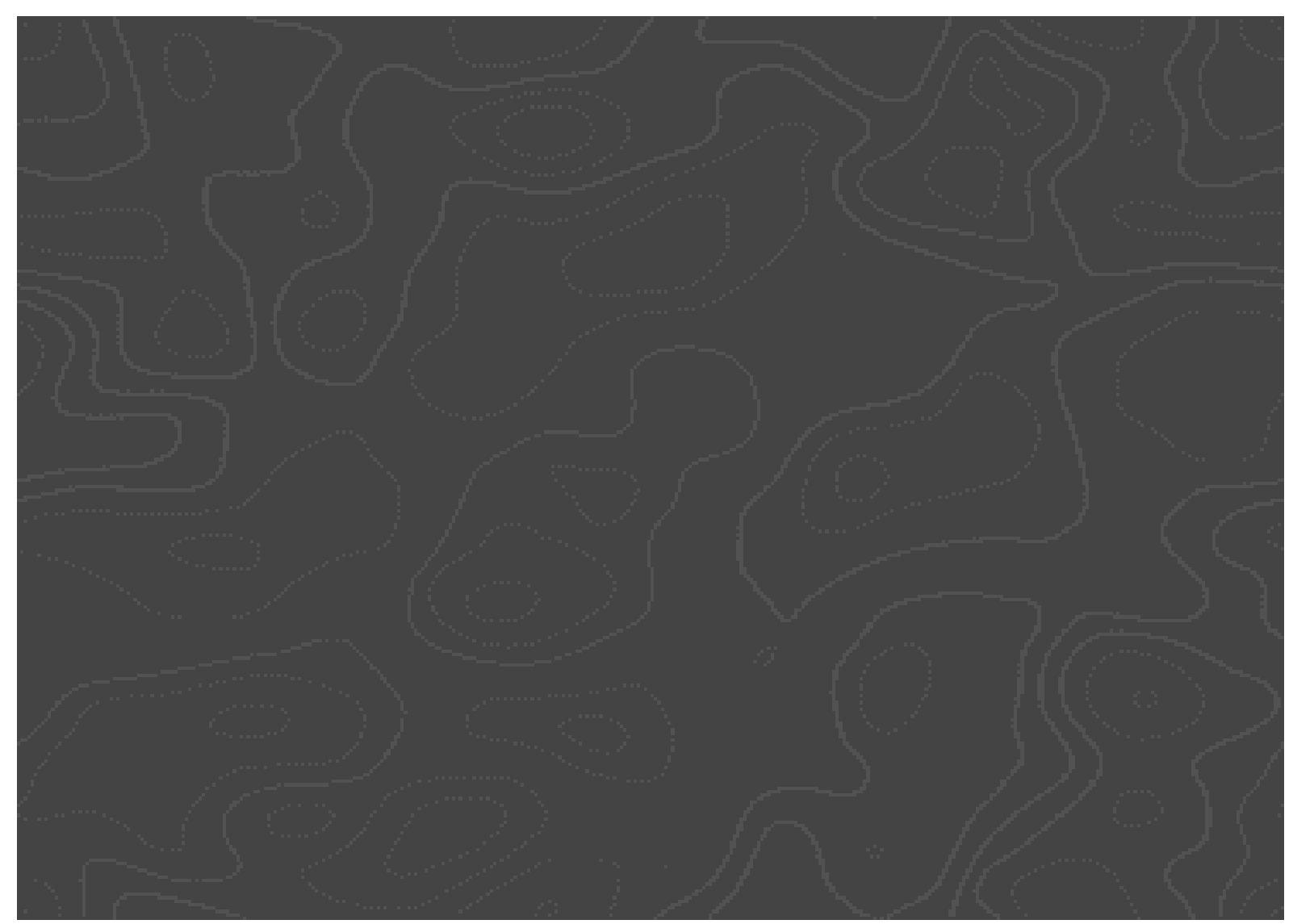

Figure 1 - i2Metrix measures for expanding survey sample

Looking closer, we can split the sample into two subsamples: i) larger-sized firms (24/40); and, ii) smaller-sized (16/40), based on the threshold of total assets size of VND 100 billion (roughly US\$4.7 million; formal exchange rate: US\$1 = VND 21,200). Figure 2 unveils the differences in values of measure through the empirical data.

The trend is clear. Larger firms appear to have been stronger in all aspects of consideration. The most significant differences between the two groups are seen in productive output, their "multi-filtering” engine, and resources such as financial expenditures and human resources dedicated to innovation process. 


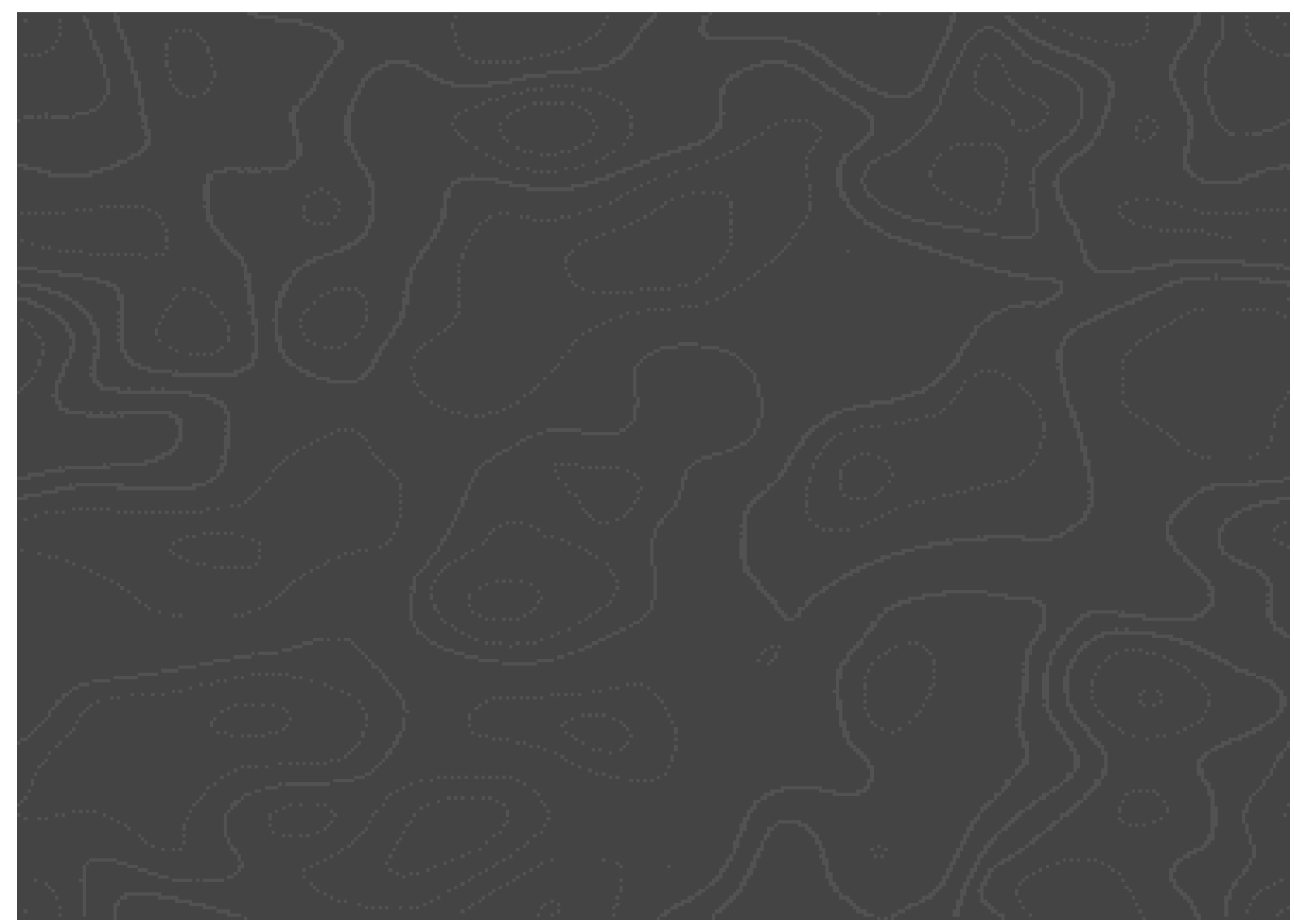

Figure 2 - i2Metrix measures for subsamples of survey data

These differences are also telling as they can be perceived distinctly in functions. Output tends to be the consequence, the results of the business process, including innovation efforts. Resources serve to be "inputs" and are purchased, procured and prepared before actual performance. Multi-filtering is the modality of work which spans different stages of business process, but the nature of its value rests with the actual processing of value, that is during the conduct of.

The question remains whether the differences are due to resources available to firms' innovation processes, or whether the innovative nature of a firm determines its size. Both factors likely contribute to the differences, but this is not captured in the survey snapshot of a complex business process that occurs over time.

Real-world interactions with entrepreneurs and corporate leaders have shown that many based their innovation efforts on personal sense and "instincts". For some periods of time, these worked well, but not always, as a systematic approach to innovation requires much more than that. Scaling up innovation activities and investments in R\&D can cause rising complication, as well as idiosyncratic risk.

Most entrepreneurs underestimated costs involved in a continuous innovation implementation program.

\section{Concluding remarks}

Innovation capacity is not about "slogans," "PR campaigns" or clichés of any sort. It is about investment in HRM, information process, strategic management determination, and entrepreneurial orientation, even if the firms undertaking it are 
well established.

Overexcitement about innovation in emerging economies can create pitfalls for not just startups and young SMEs, but also established firms, due to uncontrollability of the process and high degree of uncertainty of a typical process of making, adopting and diffusing new innovations.

Methods for better management of the innovation process have become a critical requirement for firms in their "innovating time" and they should involve some measurement and benchmarking components that help to identify areas of weakness and pitfalls, and to avoid "innovation curse" whenever possible.

There is much more to say about innovation, but the final remark should be about markets. There is no bigger risk than innovators' assumption and illusion about the abundance of lucrative opportunities out there in the market waiting for their innovative efforts. The reality has shown that there are times when existing business concepts that are applied in a new context may prove to be of significant value, and be regarded as "innovative" if there is an adequate market demand.

\section{Bibliography}

- Maddock, M. (2013). Invention: the entrepreneurial curse. Forbes, May 15.

- Napier, N. K., and Vuong, Q. H. (2013). Serendipity as a strategic advantage. In Wilkinson, T. J. (Ed.), Strategic Management in the 21st Century; Volume 1: The Operational Environment (pp. 175-199). Westport, CT: Praeger/ABC-Clio.

- Nonaka, I. (1991). The knowledge-creating company. Harvard Business Review, 69(6), 96-104.

- Schumpeter, J.A. (1994[1942]). Capitalism, Socialism and Democracy. New York, NY: Psychology Press.

- Vuong, Q.H. (2014). Vietnam's political economy: a discussion on the 1986-2016 period. Working Papers CEB, No14-010, SBS-EM, Université Libre de Bruxelles.

- Vuong, Q.H., and Napier, N.K. (2014). Making creativity: the value of multiple filters in the innovation process. International Journal of Transitions and Innovation Systems. (In press)

- Vuong, Q.H., and Napier, N.K. (2014a). Resource curse or destructive creation in transition: evidence from Vietnam's corporate sector. Management Research Review, 37(7), 642-657.

- Vuong, Q.H., Napier, N.K., and Samson, D.E. (2014). Relationship between innovations, capital expenditures, and post M\&A performance: evidence from Vietnam, 2005-2012. The IUP Journal of Business Strategy, 11(1), 34-41. 
- Vuong, Q.H., Napier, N.K., and Tran, T.D. (2013). A categorical data analysis on relationships between culture, creativity and business stage: The case of Vietnam. International Journal of Transitions and Innovation Systems, 3(1), 4-24.

- Vuong, Q.H., Napier, N.K., Tran, T.D., and Nguyen, T.H.K (2013). A categorical data analysis on financial failures in Vietnam, 2007-2013. International Journal of Business and Management, 8 (18), pp. 87-94.

- Vuong, Q.H., Napier, N.K., Vu, K.H., Nguyen, M.C., \& Tran, T.D. (2014). Measuring corporate innovation capacity: experience and implications from i2Metrix implementation in Vietnam. ASEAN Journal of Management and Innovation, 1(1), 1-17.

- Vuong, Q.H., and Tran, T.D. (2009). The cultural dimensions of the Vietnamese private entrepreneurship. IUP Journal of Entrepreneurship Development, VI(3/4), 54-7

[1] "i2Metrix" stands for "Inclusive Innovation Metrics". This name was advised by Dr. Dolly Samson (Stamford International University), during our early discussions on methodology and design in early 2014.

* Vuong, Q.H. (2014). The Harsh Reality of Pursuing Innovations: Emerging Market Perspectives. Proceedings of The Second National Conference on Management and Higher Education Trends \& Strategies for Management \& Administration, October 31 - November 1, Stamford International University, Bangkok - Thailand

Dr. Dolly Samson and Dr. Vuong Quan Hoang. 


\section{Subscribe to Intelligence Over News}

Independent Strategic Analysis | Objective Geopolitical Insights

\section{Start your subscription today!}

\section{Article Search}

\#

Copyright (c) Stratfor Enterprises, LLC. All rights reserved. 


\section{References}

Maddock, M. (2013). Invention: the entrepreneurial curse. Forbes, May 15.

Napier, N. K., and Vuong, Q. H. (2013). Serendipity as a strategic advantage. In Wilkinson, T. J . (Ed.), Strategic Management in the 21st Century; Volume 1: The Operational Environment (pp. 175-199). Westport, CT: Praeger/ ABC-Clio.

Nonaka, I. (1991). The knowledge-creating company. Harvard Business Review, 69(6), 96-104.

Schumpeter, J .A. (1994[1942]). Capitalism, Socialism and Democracy. New York, NY: Psychology Press.

Vuong, Q.H. (2014). Vietnam's political economy: a discussion on the 1986-2016 period. Working Papers CEB, №14-010, SBS-EM, Université Libre de Bruxelles.

Vuong, Q.H., and Napier, N.K. (2014). Making creativity: the value of multiple filters in the innovation process. International J ournal of Transitions and Innovation Systems. (In press)

Vuong, Q.H., and Napier, N.K. (2014a). Resource curse or destructive creation in transition: evidence from Vietnam's corporate sector. Management Research Review, 37(7), 642-657.

Vuong, Q.H., Napier, N.K., and Samson, D.E. (2014). Relationship between innovations, capital expenditures, and post M\&A performance: evidence from Vietnam, 20052012. The IUP J ournal of Business Strategy, 11(1), 34-41.

Vuong, Q.H., Napier, N.K., and Tran, T.D. (2013). A categorical data analysis on relationships between culture, creativity and business stage: The case of Vietnam. International J ournal of Transitions and Innovation Systems, 3(1), 4-24.

Vuong, Q.H., Napier, N.K., Tran, T.D., and Nguyen, T.H.K (2013). A categorical data analysis on financial failures in Vietnam, 2007-2013. International J ournal of Business and Management, 8 (18), pp. 87-94.

Vuong, Q.H., Napier, N.K., Vu, K.H., Nguyen, M.C., \&Tran, T.D. (2014). Measuring corporate innovation capacity: experience and implications from i2Metrix implementation in Vietnam. ASEAN J ournal of Management and Innovation, 1(1), 1-17.

Vuong, Q.H., and Tran, T.D. (2009). The cultural dimensions of the Vietnamese private entrepreneurship. IUP J ournal of Entrepreneurship Development, VI(3/4), 54-7 